Article

\title{
An Experimental Study of Portland Cement and Superfine Cement Slurry Grouting in Loose Sand and Sandy Soil
}

\author{
Weijing Yao ${ }^{\mathbb{D}}$, Jianyong Pang * and Yushan Liu \\ School of Civil Engineering and Architecture, Anhui University of Science and Technology, \\ Huainan 232001, China; yaoweijing0713@163.com (W.Y.), liuyushan1997@126.com (Y.L.) \\ * Correspondence: jypang@aust.edu.cn; Tel: +86-0554-6668528
}

Received: 5 March 2018; Accepted: 6 April 2018; Published: 12 April 2018

\begin{abstract}
Grouting technology is widely applied in the fields of geotechnical engineering in infrastructure. Loose sand and sandy soil are common poor soils in tunnel and foundation treatments. It is necessary to use superfine cement slurry grouting in the micro-cracks of soil. The different effectiveness of Portland cement slurry and superfine cement slurry in sandy soil by the laboratory grouting experiment method were presented in this paper. The grouting situations of superfine cement slurry injected into sand and sandy soil were explored. The investigated parameters were the dry density, wet density, moisture content, internal friction angle, and cohesion force. The results show that the consolidation effect of superfine cement is better than that of Portland cement due to the small size of superfine cement particles. The superfine cement can diffuse into the sand by infiltration, extrusion, and splitting. When the water-cement ratio of superfine cement slurry is less than 2:1 grouting into loose sand, the dry and wet density decrease with the increase in the water-cement ratio, while the moisture content and cohesive force gradually increase. When the water-cement ratio of superfine cement slurry is 1:1 grouting into loose sand and sandy soil, the dry density, wet density, and cohesive force of loose sand are larger than those of sandy soil. The results of the experiment may be relevant for engineering applications.
\end{abstract}

Keywords: Portland cement; superfine cement; loose sandy soil; grouting; model experiment

\section{Introduction}

Grouting is a common technology in geotechnical engineering in infrastructure. The grouting slurry is injected into cracks in rock and soil, the slurry is cemented to the rock and soil by filling, permeation, compaction, and splitting, which improves the mechanical properties, stability, integrity, and strength of the rock and soil [1-5]. In 1802, Charles Berigny first used the grouting method for the repair of the Dieppe gate [6]. The grouting technique has been introduced into many countries and applied more and more widely. It has been popularized in railway, highway, coal, geology, water and electricity, military and other industries and has infiltrated into underground engineering, including foundation reinforcement, grouting water plugging, backfill, sinking control, housing rectification, landslide prevention, deformation control, landslide treatment, water cut-off curtain, seepage treatment, dam foundation seepage prevention, seepage control, ancient building protection and crack repair, etc. [7-10]. However, the design of grouting parameters and the test of grouting effect are quite difficult due to the concealment of grouting engineering and the complexity of underground engineering structure. However, laboratory experiments are an effective method of determining the grouting parameters and the effectiveness of various factors on the grouting effects [11-13]. Simultaneously, loose sand and sandy soil are a common poor stratum in foundation treatment, 
tunnel and shaft engineering. It is required that the injected slurry form continuous and stable cementation $[14,15]$. For a soil layer with small particle size, the commonly used Portland cement slurry often cannot be grouted into the micro-cracks of soil, which cannot form an effective waterproof curtain. While the superfine cement has the advantages of high strength, good durability, and non-toxicity, it can be injected into the fine sand formation of the permeability coefficient lower than $10^{-2} \mathrm{~cm} / \mathrm{s}$ due to its small particle size [16-18].

Therefore, this article adopted the method of laboratory experiment and comparatively studied the grouting effect of Portland cement and superfine cement slurry grouting into loose sand and sandy soil. The grouting effect of superfine cement grouting the sand and sandy soil was explored, providing reference for the related engineering practice.

\section{Equipment and Materials}

\subsection{Equipment}

The experimental equipment includes a grouting test chamber, grouting equipment, and monitoring equipment. It is connected by a grouting test chamber, a grouting pipe, a grouting pump, an agitator, a high-pressure hose, a ball valve, a pressure gauge, and a stopwatch. The connection schematic is shown in Figure 1. The grouting test chamber is composed of five pieces of steel plate, with the upper opening being cubic in shape with a size of $45 \mathrm{~cm} \times 45 \mathrm{~cm} \times 45 \mathrm{~cm}$. The upper cover and lower plate are detachable. The grouting test chamber is fixed by two pairs of binding rod when grouting and when the center of the cover is open the grouting hole has a diameter of $30 \mathrm{~mm}$, as shown in Figure 2. Due to the test chamber being small in size, large in thickness, high in pressure, and airtight, it can be applied to compaction grouting tests with high pressure ratio and higher water content.

The grouting pump provides grouting pressure; the equipment adopted a pneumatic grouting pump with a working pressure of $0 \sim 3 \mathrm{MPa}$ and a nominal flow rate of $1.0 \sim 3.6 \mathrm{~L} / \mathrm{min}$. The length of the grouting pipe is $50 \mathrm{~cm}$ and the diameter is $30 \mathrm{~mm}$. As shown in Figure 3 , in the middle range $(30 \mathrm{~cm})$ of the entire pipe, there are some round holes with a diameter of $5 \mathrm{~mm}$ at the interval of $100 \mathrm{~mm}$.

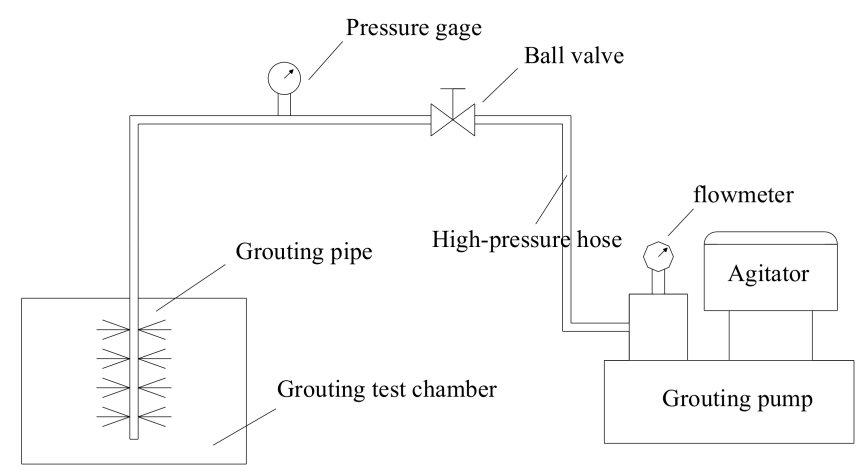

Figure 1. The experiment equipment of grouting simulation.

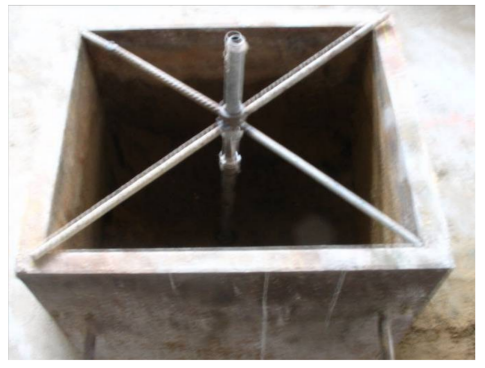

Figure 2. Grouting test chamber. 


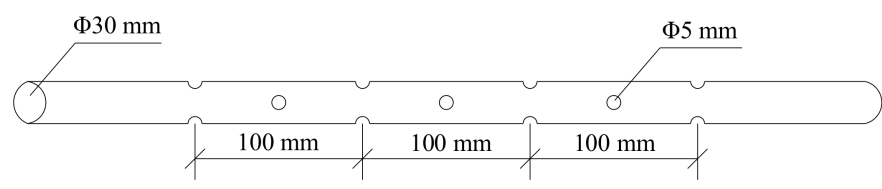

Figure 3. The construction of grouting pipe.

\subsection{Materials}

Two kinds of materials were used, natural medium sand from Huaihe in China and sand mixed with $10 \%$ clay in loose sand. The related parameters of the two materials measured by the laboratory are shown in Table 1.

Table 1. The related parameters of sand and sandy soil.

\begin{tabular}{cccccc}
\hline Materials & Elasticity Modulus/MPa & Poisson Ratio & Void Ratio & Unit Weight $/ \mathbf{k g} \cdot \mathbf{m}^{-\mathbf{3}}$ & Moisture Content $/ \%$ \\
\hline Sand & 18 & 0.3 & 0.39 & 1750 & 10 \\
Sandy soil & 20 & 0.3 & 0.35 & 1750 & 10 \\
\hline
\end{tabular}

The superfine cement slurry and Portland cement slurry used as grouting materials were produced by the Three Lions Special Cement Company and Pagongshan Company in China, grade 42.5. The specific surface area of superfine cement is more than $900 \mathrm{~m}^{2} / \mathrm{kg}$, with a minimum particle size of $1.94 \mu \mathrm{m}$ and a maximum particle size less than $30 \mu \mathrm{m}$; the average particle size is less than $5 \mu \mathrm{m}$. The Portland cement specific surface is about $600 \sim 650 \mathrm{~m}^{2} / \mathrm{kg}$. Their performance indicators are shown in Table 2.

Table 2. The performance indicators of grouting slurry.

\begin{tabular}{|c|c|c|c|c|c|}
\hline Parameters & $\begin{array}{c}\text { Volume } \\
\text { Mass } / \mathrm{kg} \cdot \mathrm{L}^{-1}\end{array}$ & $\begin{array}{l}\text { Water } \\
\text { Absorption } \\
\text { of } 2 \mathrm{~h} / \mathrm{h}\end{array}$ & $\begin{array}{l}\text { Marsh Funnel } \\
\text { Viscosity/Pa·s }\end{array}$ & Cohesion $/ \mathbf{N} \cdot \mathrm{m}^{-2}$ & $\begin{array}{c}\text { The Slurry } \\
\text { Body Strength } \\
\text { of } 28 \mathrm{~d} / \mathrm{MPa}\end{array}$ \\
\hline $\begin{array}{c}\text { The superfine cement } \\
\text { slurry of water-cement } \\
\text { ratio } 1: 1\end{array}$ & 1.53 & $<5$ & $<35$ & $<4$ & $>15$ \\
\hline $\begin{array}{c}\text { The superfine cement } \\
\text { slurry of water-cement } \\
\text { ratio } 2: 1\end{array}$ & 1.27 & $<6$ & $<30$ & $<4$ & $>12$ \\
\hline $\begin{array}{c}\text { The Portland cement } \\
\text { slurry of water-cement } \\
\text { ratio } 1: 1\end{array}$ & 2.01 & $<4$ & $<40$ & $<4$ & $>12$ \\
\hline
\end{tabular}

\section{Methods}

First of all, the experiment model and grouting materials were prepared for use. Then the soil was stratified, filling by $5 \mathrm{~cm}$ at a time. The model was loaded nine times and then the upper cover and binding rod were installed, as shown in Figure 4. Finally, the grouting pipeline system was connected and the grouting pipeline system was tested with clean water. 


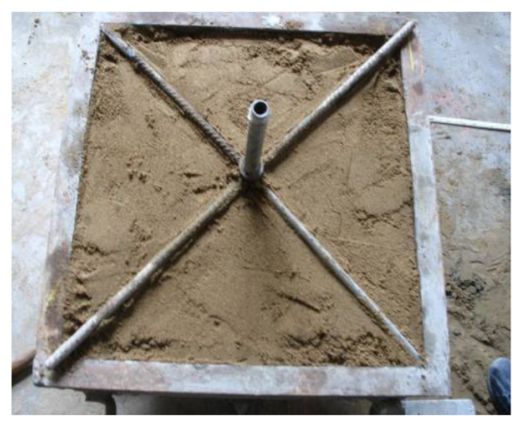

Figure 4. The experimental chamber after filling.

Superfine cement and Portland cement were used as grouting materials; sand and sandy soil mixed with $10 \%$ clay were used as injected soil. The grouting pressure was $1.0 \mathrm{MPa}$ and the pressure gauge was used to measure the grouting pressure. The test was carried out under constant grouting pressure until the model ceased to absorb slurry. After the grouting experiment, the chamber was held for 2-3 days before it was dismantled [19]. The physical and mechanical properties of the soil were tested by sampling, and the diffusion mechanism of slurry in the soil was studied. The method of ring-knife sampling of layered excavation was used to achieve the test point set location; the diameter of the ring-knife is $60 \mathrm{~mm}$ and the height is $20 \mathrm{~mm}$. Each downward excavation is 1-2 cm, avoiding disturbing undisturbed soil samples. There are eight measure points in each group, as shown in Figure 5. There are four layers in the vertical direction, starting from the edge of the test chamber, and the depths are $5 \mathrm{~cm}, 15 \mathrm{~cm}, 25 \mathrm{~cm}$, and $35 \mathrm{~cm}$. In the radial direction, four points were arranged in each layer, and the distance of the grouting pipe is $8 \mathrm{~cm}$ and $16 \mathrm{~cm}$, respectively. A total of 32 samples were taken from each group. Then soil samples were tested for shear strength, moisture content, dry density, and other related parameters.
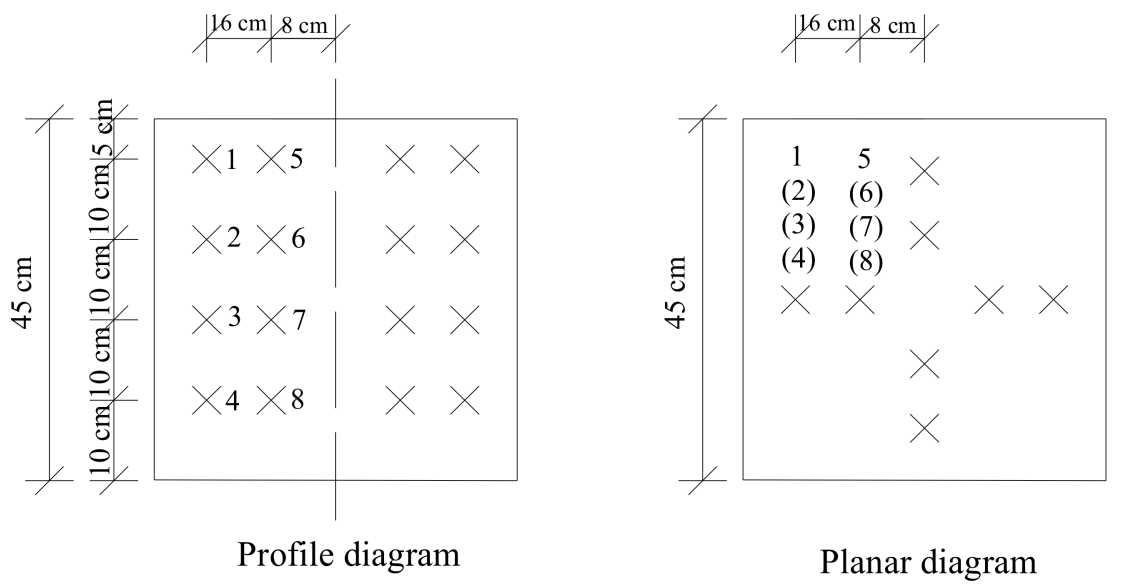

Figure 5. The arrangement schematic of soil sampling point.

\section{Results and Analysis}

\subsection{Analysis}

In the experiment, the grouting pressure gradually increased until it reached the target pressure. In the process of increasing, instability often occurred, which can be attributed to the fluctuation of the pressure value of the slurry from the grouting pump. In addition, the slurry flowing through the soil alternately encounters larger skeleton pores such as clay particles and fine particles such as sand, causing the pressure to fluctuate [20-22]. 
It was found that the superfine cement slurry grouted into soil was well cemented with the injected medium after being fully consolidated. The typical shape of the concrete body could be divided into spherical, columnar, and flaky types, presented in Figure 6.

Among them, Figure $6 \mathrm{a}$ is the case where the water-cement ratio of superfine cement slurry is $1: 1$ and the grouting pressure is $1.0 \mathrm{MPa}$ in loose sand; Figure $6 \mathrm{~b}$ is the case where the water-cement ratio of superfine cement slurry is 2:1 and the grouting pressure is $1.0 \mathrm{MPa}$ in loose sand; Figure $6 \mathrm{c}$ is the case where the water-cement ratio of superfine cement slurry is 2:1 and the grouting pressure is 1.0 MPa in sandy soil mixed with $10 \%$ clay. From the test consolidation, the superfine cement slurry can be grouted into sand and sandy soil under different water-cement ratios. It can diffuse into the soil in the form of penetration, compaction, and splitting, which consolidates the soil and improves the strength and cohesion.

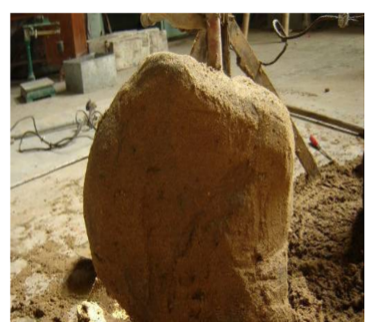

(a) Spherical

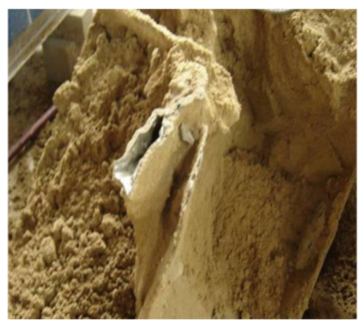

(b) flaky

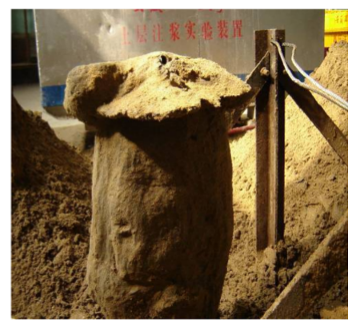

(c) cylindrical

Figure 6. The soil shape of grouting superfine cement slurry.

Comparing with the Portland cement grouting into sandy layer, the grouting effect is shown in Figure 7. It is observed that the Portland cement slurry concrete body volume is small and the boundary of slurry and soils is clear, making it almost impossible to inject slurry. Ordinary cement slurry penetration and diffusion in sandy soil is very difficult due to its coarse particles. It tends to extrude the soil around the grouting pipe to a distant place so as to meet the purpose of soil consolidation. The ordinary cement slurry cannot be injected and the soil cannot be squeezed and reinforced due to the test chamber being so small. However, because of the fine particles of superfine cement slurry, the grouting effect is better through the formation of infiltration grouting to reinforce the soil.

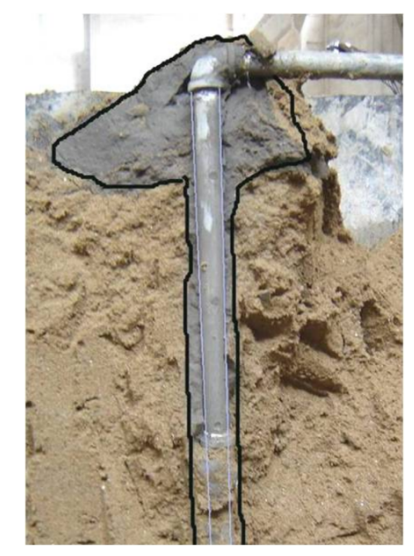

Figure 7. A cross section view of Portland cement slurry grouting into sandy soil.

\subsection{Mechanics Performance Analysis of Grouting Soil}

The experiment is divided into three groups. The physical and mechanical properties of soil samples were tested, including dry density, wet density, moisture content, internal friction angle, 
and cohesive force [23]. The drying method was used to test moisture content. The wet density was measured directly after the ring-knife sampling, and the dry density was measured after hammering and drying. The cohesive and internal friction angles were obtained by a direct shear test. The mean values were calculated from experimental data and listed in Tables 3-5. The details of the three groups are as follows.

Group One: Superfine cement slurry of water-cement ratio 1:1, grouting pressure 1.0 MPa, injection sand.

Group Two: Superfine cement slurry of water-cement ratio 2:1, grouting pressure 1.0 MPa, injection sand.

Group Three: Superfine cement slurry of water-cement ratio 1:1, grouting pressure 1.0 MPa, injection sandy soil mixed with $10 \%$ clay.

Table 3. The mechanical properties of grouting soil in Group One.

\begin{tabular}{|c|c|c|c|c|c|}
\hline $\begin{array}{c}\text { Number of } \\
\text { Measuring Points }\end{array}$ & $\begin{array}{c}\text { Dry } \\
\text { Density } / \mathrm{g} \cdot \mathrm{cm}^{-3}\end{array}$ & $\begin{array}{c}\text { Wet } \\
\text { Density } / \mathrm{g} \cdot \mathrm{cm}^{-3}\end{array}$ & $\begin{array}{c}\text { Moisture } \\
\text { Content } \%\end{array}$ & $\begin{array}{c}\text { Internal } \\
\text { Friction Angle/ }^{\circ}\end{array}$ & $\begin{array}{c}\text { Cohesive } \\
\text { Force/MPa }\end{array}$ \\
\hline 1 & 1.65638 & 1.75212 & 5.78 & 28.13729 & 0.020 \\
\hline 2 & 1.74422 & 1.88498 & 8.07 & 30.19861 & 0.096 \\
\hline 3 & 1.75676 & 1.95844 & 11.48 & 29.83082 & 0.311 \\
\hline 4 & 1.71426 & 1.95700 & 14.16 & 27.45718 & 0.427 \\
\hline 5 & 1.79678 & 1.93136 & 7.49 & 31.43870 & 0.057 \\
\hline 6 & 1.81562 & 1.98356 & 9.25 & 32.27310 & 0.156 \\
\hline 7 & 1.81380 & 2.05485 & 13.29 & 32.37840 & 0.455 \\
\hline 8 & 1.79696 & 2.11089 & 17.47 & 29.58446 & 0.526 \\
\hline
\end{tabular}

Table 4. The mechanical properties of grouting soil in Group Two.

\begin{tabular}{cccccc}
\hline $\begin{array}{c}\text { Number of } \\
\text { Measuring Points }\end{array}$ & $\begin{array}{c}\text { Dry } \\
\text { Density/g.cm }\end{array}$ & $\begin{array}{c}\text { Wet } \\
\text { Density/g.cm }\end{array}$ & $\begin{array}{c}\text { Moisture } \\
\text { Content/\% }\end{array}$ & $\begin{array}{c}\text { Internal } \\
\text { Frictio Angle/ }\end{array}$ & $\begin{array}{c}\text { Cohesive } \\
\text { Force/MPa }\end{array}$ \\
\hline 1 & 1.64114 & 1.73977 & 9.47 & 27.36077 & 0.030 \\
2 & 1.71798 & 1.85852 & 14.85 & 29.45473 & 0.155 \\
3 & 1.73059 & 1.90002 & 17.48 & 31.19078 & 0.356 \\
4 & 1.64623 & 1.90124 & 18.90 & 30.82560 & 0.425 \\
5 & 1.63017 & 1.76352 & 11.10 & 30.68656 & 0.052 \\
6 & 1.71464 & 1.88816 & 15.25 & 32.04380 & 0.185 \\
7 & 1.72052 & 1.98772 & 18.36 & 33.84496 & 0.500 \\
8 & 1.66338 & 1.96794 & 19.73 & 32.97151 & 0.552 \\
\hline
\end{tabular}

Table 5. The mechanical properties of grouting soil in Group Three.

\begin{tabular}{cccccc}
\hline $\begin{array}{c}\text { Number of } \\
\text { Measuring Points }\end{array}$ & $\begin{array}{c}\text { Dry } \\
\text { Density/g.cm }\end{array}$ & $\begin{array}{c}\text { Wet } \\
\text { Density/g.cm }\end{array}$ & $\begin{array}{c}\text { Moisture } \\
\text { Content/\% }\end{array}$ & $\begin{array}{c}\text { Internal } \\
\text { Friction Angle/ }\end{array}$ & $\begin{array}{c}\text { Cohesive } \\
\text { Force/MPa }\end{array}$ \\
\hline 1 & 1.55026 & 1.69707 & 6.01 & 25.47224 & 0.049 \\
2 & 1.57527 & 1.80920 & 8.18 & 29.67818 & 0.121 \\
3 & 1.57653 & 1.85211 & 9.79 & 31.07645 & 0.155 \\
4 & 1.56531 & 1.86115 & 15.49 & 30.08660 & 0.253 \\
5 & 1.58581 & 1.76183 & 8.18 & 29.68110 & 0.075 \\
6 & 1.59846 & 1.84223 & 10.12 & 31.60698 & 0.156 \\
7 & 1.60663 & 1.90161 & 15.53 & 33.47386 & 0.255 \\
8 & 1.59604 & 1.91094 & 18.31 & 33.57000 & 0.324 \\
\hline
\end{tabular}

Comparing the test data of Group One and Group Two, superfine cement slurry with different water-cement ratios is injected into the loose sand under a grouting pressure of $1.0 \mathrm{MPa}$. The relevant mechanical properties of the grouted soil were studied, including different grouting radius of $8 \mathrm{~cm}$ and $16 \mathrm{~cm}$, as presented in Figure 8. 


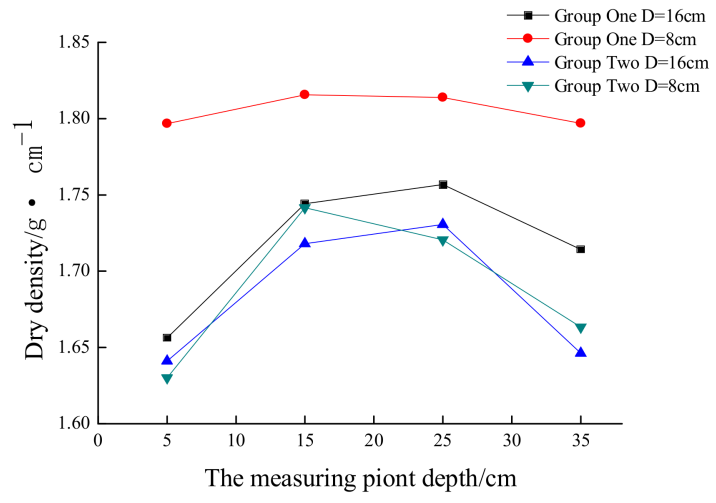

(a) Dry density

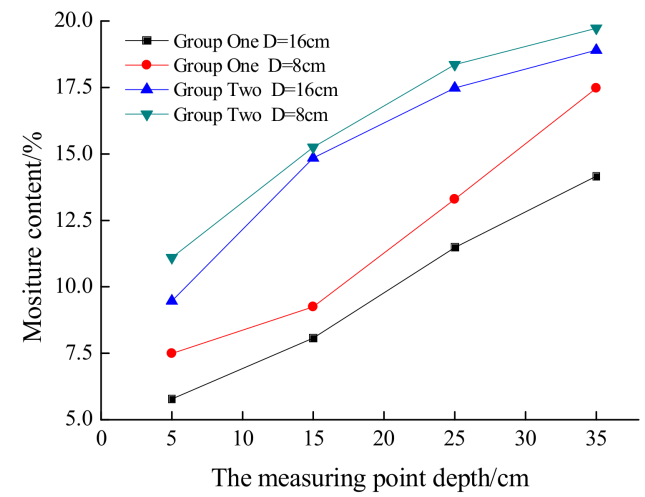

(c) Moisture content

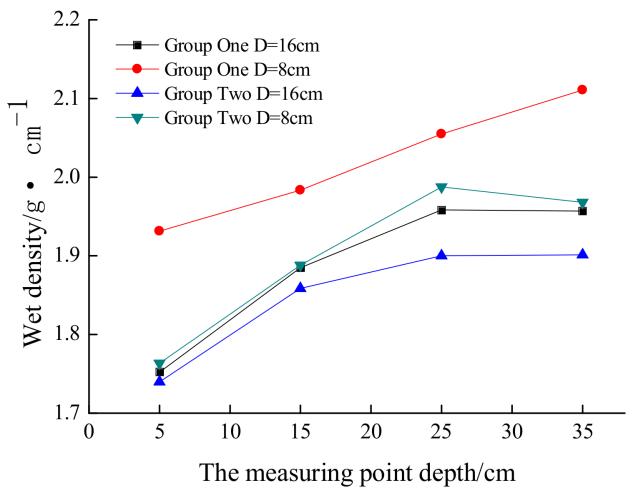

(b) Wet density

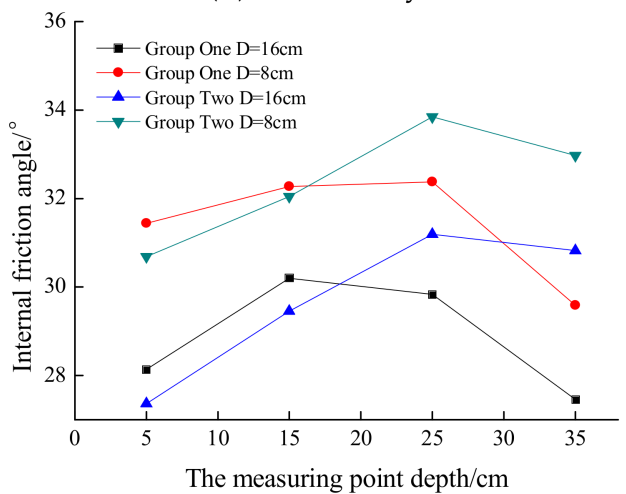

(d) Internal friction angle

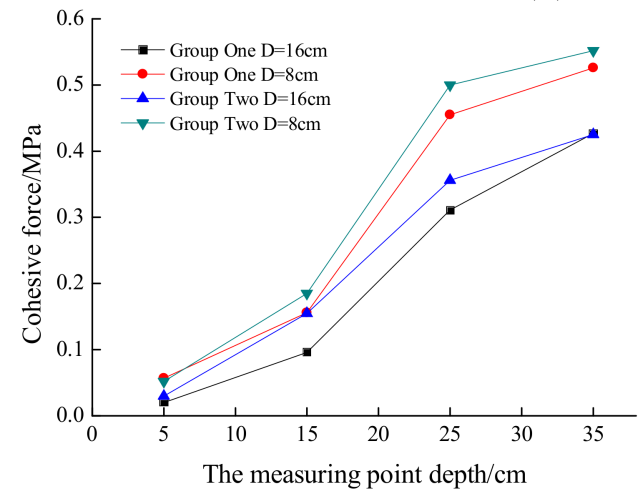

(e) Cohesive force

Figure 8. A comparison of the mechanical properties of grouting soil in Group One and Group Two.

From Tables 3 and 4, it can be seen that the compactness of soil is quite different under different water-cement ratio grouting conditions. The dry density and wet density of Group One are about 4\% larger than those of Group Two, while the cohesive force of Group Two is about 10\% larger than in Group One. The results presented in Figure 8 show that the larger the water-cement ratio is, the smaller the dry and wet density, and the higher the moisture content and cohesion.

The effect of diffusion and reinforcement of the injected medium is different because of the different water-cement ratio. The diffusion ability of Portland cement in the sand is small due to the smaller water-cement ratio and the larger concentration. The reinforcement mainly relies on the grouting pressure extrusion. While superfine cement slurry diffuses well in loose sand, it mainly relies on the slurry infiltrating into the interstices between particles under pressure. The extrusion mainly strengthens the compactness of soil, while the infiltration grouting mainly enhances the cohesion of soil. 
The results presented in Figure 8 show that the moisture content and cohesive force of the soil increased with the depth of the measuring point. The maximum of dry density, wet density, and internal friction angle appeared in the vertical middle of the grouting pipe and gradually decreased along with the grouting pipe. In the same horizontal plane, the physical and mechanical performance indexes of grouting radius $8 \mathrm{~cm}$ are better than radius $16 \mathrm{~cm}$. The bigger the grouting radius is, the more obvious the attenuation effect is.

Comparing the test data of Group One and Group Three, the superfine cement slurry with the same water-cement ratio is injected into sand and sandy soil mixed with $10 \%$ clay under the grouting pressure of 1.0 MPa. The relevant mechanical properties of the grouted soil are presented in Figure 9.

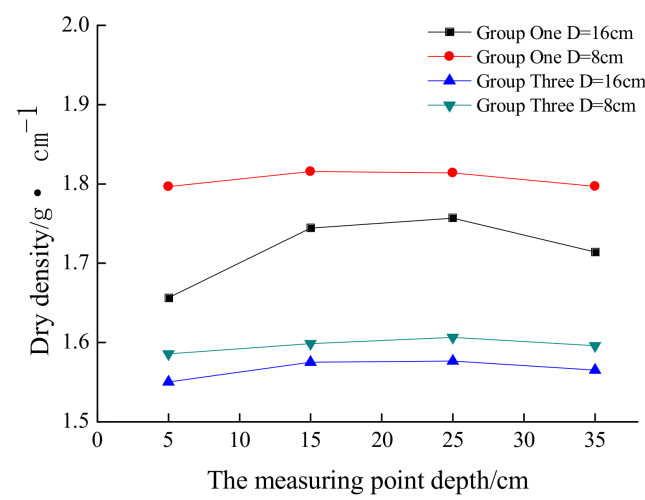

(a) Dry density

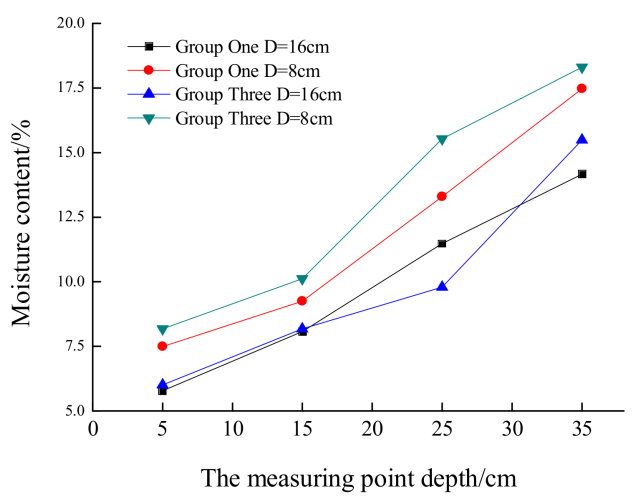

(c) Moisture content

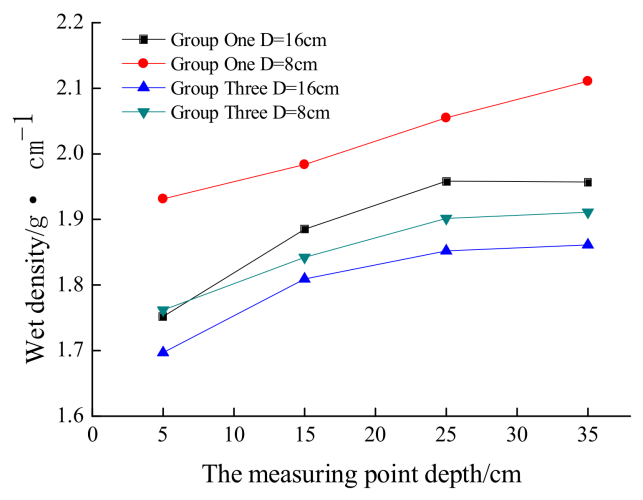

(b) Wet density

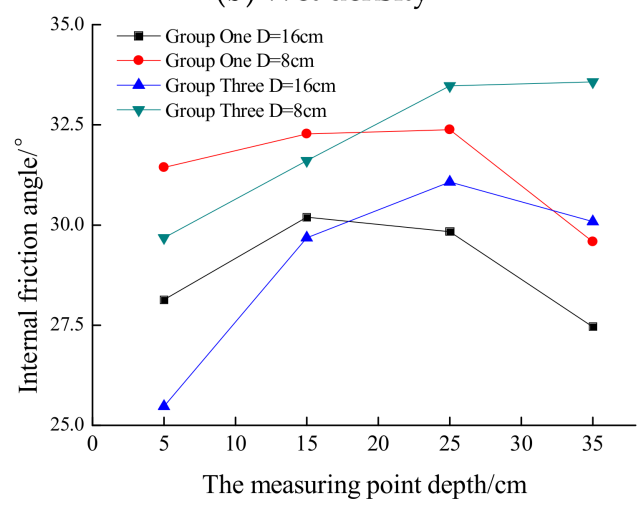

(d) Internal friction angle

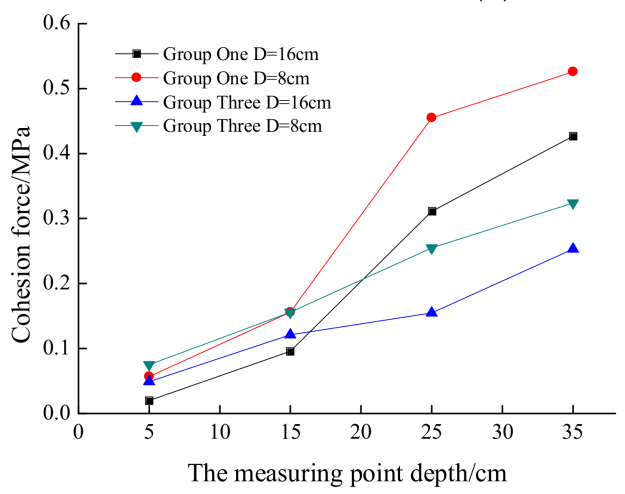

(e) Cohesive force

Figure 9. A comparison of the mechanical properties of grouting soil in Group One and Group Three.

Tables 3 and 5 show that the dry density of superfine cement injection sand improved by about $10 \%$ over injection sandy soil, while the wet density improved by $6 \%$ and the cohesive force improved 
by about $30 \%$. The results presented in Figure 9 show that the dry density, wet density, and cohesive force of the soil are obviously larger than for sandy soil, the moisture content of which is slightly larger than for sand.

Due to the particle size of the clay being significantly larger than that of pure sand, there are skeleton pores made of clay in the sandy soil after $10 \%$ clay is incorporated. The dry density, wet density, and cohesive force of consolidation formed by grouting of loose sand are significantly larger than those of sandy soil. This can explain the obvious difference between the injection effect of slurry in loose sand and sandy soil.

From Figure 9, it can be seen that the moisture content and cohesive force of the soil increased with the depth of the measured point. The maximum of dry density, wet density, and internal friction angle still appeared in the vertical middle of the grouting pipe and gradually decreased along with the grouting pipe, but the rule is not as obvious as for Group One and Group Two. In the same horizontal plane, the physical and mechanical performance indexes of grouting radius $8 \mathrm{~cm}$ are better than radius $16 \mathrm{~cm}$. This is in accordance with the rule of Group One and Group Two.

\section{Conclusions}

(1) In view of the status of the superfine cement treatment of loose sand and sandy soil, a laboratory test was conducted to compare the injection effects of Portland cement and superfine cement on sandy soil. The results show that the superfine cement slurry consolidation effect of sandy soil is better and the strength is improved because the superfine cement particles diffuse in the form of infiltration, extrusion, and splitting. However, the Portland cement can hardly be injected and diffused into the sandy soil. This indicates that superfine cement slurry is effective for reinforcing the sandy soil.

(2) Three groups of experiments were designed to study the effect of superfine cement slurry injection. The results show that the superfine cement slurry grouted into sand or sandy soil can significantly improve the physical and mechanical properties of the injected medium. When the water-cement ratio of superfine cement slurry is less than 2:1 grouting into loose sand, the dry and wet density decrease with the increase in the water-cement ratio while the moisture content and cohesive force increase gradually. Compared with the same water-cement ratio of 1:1, the grouting effect of slurry injection sand and sandy soil, the dry density, wet density, and cohesive force of sand are significantly larger than for sandy soil.

Acknowledgments: The writers gratefully acknowledge the financial support provided by the Major Program of Colleges and Universities Natural Science Foundation of Anhui Province, China (KJ2015ZD20), the Major Innovation Platform and Innovative Talents Team of Colleges and Universities of Huainan Science and Technology Plan (2017A055), and the Graduate Student Innovation Foundation of Anhui University of Science and Technology, China (2017CX1006) for this study.

Author Contributions: Weijing Yao and Jianyong Pang performed the experiments and analyzed the test data; Weijing Yao and Yushan Liu wrote the manuscript; Jianyong Pang conceived the experiment and provided the guidance and suggestion.

Conflicts of Interest: The authors declare no conflict of interest.

\section{References}

1. Gullu, H. A new prediction method for the rheological behavior of grout with bottom ash for jet grouting columns. Soils Found. J. 2017, 57, 384-396. [CrossRef]

2. Kogler, K. Grouting technology in tunnelling. Geomech. Tunnelbau J. 2013, 6, 261-273. [CrossRef]

3. Bellendir, E.N.; Aleksandrov, A.V.; Zertsalov, M.G.; Simutin, A.N. Building and structure protection and leveling using compensation grouting technology. Power Technol. Eng. J. 2016, 50, 142-146. [CrossRef]

4. Jiang, Y.S. Application and development of modern grouting technology. Mod. Tunn. Technol. J. 2008, 45, 6-10. (In Chinese with English Abstract) 
5. Yang, M.J.; Chen, M.X.; He, Y.N. Current research state of grouting technology and its development direction in future. Chin. J. Rock Mech. Eng. J. 2001, 20, 839-841. (In Chinese with English Abstract)

6. Chen, X.; Zhang, F.X. Construct and Effect Inspect of Grouting in Engineering; Tongii University Press: Shanghai, China, 1998. (In Chinese)

7. Zhang, M.Q.; Zhang, W.Q.; Sun, G.Q. Evaluation technique of grouting effect and its application to engineering. Chin. J. Rock Mech. Eng. J. 2006, 25, 3909-3918. (In Chinese with English Abstract)

8. Wang, Z.S.; Zhang, D.J. Key technology on shallow embedded tunnel constructed beneath existing subway tunnel. Chin. J. Rock Mech. Eng. J. 2007, 26, 4208-4214. (In Chinese with English Abstract)

9. Feng, Z.Q.; Kang, H.P.; Yang, J.H. Discussion on grouting technology of fractured rock mass. Coal Sci. Technol. J. 2005, 33, 63-66. (In Chinese)

10. Burke, G.K.; Cacoil, D.M.; Chadwick, K.R. Superjet grouting: New technology for in situ soil improvement. Transp. Res. Rec. J. 2000, 1721, 45-53. [CrossRef]

11. Ge, J.L.; Lu, S.L. Study on grouting simulation experiment and its application. Chin. J. Geotech. Eng. J. 1997, 19, 28-33. (In Chinese with English Abstract)

12. Ge, J.L. The Study of Grouting Reinforcement Mechanism and Technology of Soft Rock Roadways; China University of Mining and Technology: Xuzhou, China, 1995. (In Chinese)

13. Bouchelaghem, F. Multi-scale modelling of the permeability evolution of fine sand during cement suspension grouting with filtration. Comput. Geotech. J. 2009, 36, 1058-1071. [CrossRef]

14. Kim, J.W.; Chough, S.K. A gravel lobe deposit in the prodelta of the Doumsan Fan Delta (Miocene), SE Korea. Sediment. Geol. J. 2000, 130, 183-203. [CrossRef]

15. Vincent, P.; Sadah, A. Fabric analyses of some Saudi Arabian pediment gravels. J. Arid Environ. J. 1995, 30, 371-384. [CrossRef]

16. Avci, E.; Mollamahmutoglu, M. Permeability characteristics of superfine cement-grouted sand. ACI Mater. J. 2017, 114, 21-28. [CrossRef]

17. Fransson, A. Characterisation of a fractured rock mass for a grouting field test. Tunn. Undergr. Space Technol. J. 2001, 16, 331-339. [CrossRef]

18. Wu, A.X.; Yu, S.F.; Han, B.; Wang, Y.M.; Huang, M.Q.; Wang, Y. Optimization of mix-proportion and diffusing rule of super-fine cement grouting slurry. J. Min. Saf. Eng. J. 2014, 31, 304-309. (In Chinese with English Abstract)

19. Xu, S.H.; Xing, L.L.; Wang, G.Q.; Han, Q. Experimental research on grouting of superfine cement slurry in micro-fissured rock body. J. Saf. Sci. Technol. J. 2014, 10, 96-102. (In Chinese with English Abstract)

20. Yang, P.; Tang, Y.Q.; Peng, Z.B.; Chen, A. Study on grouting simulating experiment in sandy gravels. Chin. J. Geotech. Eng. J. 2006, 28, 2134-2138. (In Chinese with English Abstract)

21. Zhang, Z.M.; Zou, J.; He, J.Y.; Wang, H.Q. Laboratory tests on compaction grouting and fracture grouting of clay. Chin. J. Geotech. Eng. J. 2009, 31, 1818-1824. (In Chinese with English Abstract)

22. Zhang, W.J.; Li, S.C.; Wei, J.C.; Zhang, Q.S.; Zhang, X.; Li, Z.P.; Xie, D.L. Development of a 3D grouting model test and its application. Rock Soil Mech. J. 2016, 37, 902-911. (In Chinese with English Abstract)

23. Research Institute of Highway Ministry of Transport. Test Methods of Soils for Highway Engineering JTG E40-2007; Research Institute of Highway Ministry of Transport: Beijing, China, 2007. (In Chinese)

(C) 2018 by the authors. Licensee MDPI, Basel, Switzerland. This article is an open access article distributed under the terms and conditions of the Creative Commons Attribution (CC BY) license (http:/ / creativecommons.org/licenses/by/4.0/). 